\title{
Work, fit notes, and occupational health
}

In the current age of austerity, governments around the world are looking at ways to reduce public spending. In the UK, attention has recently focused on trying to reduce the huge cost to the economy of supporting people of working age who have stopped working for health reasons. ${ }^{1}$ A range of initiatives and policies that encourage people back to work have been introduced in the UK. Government initiatives have included replacing Incapacity Benefit, Income Support, and Severe Disablement Allowance, with Employment Support Allowance from October 2008. ${ }^{2}$ It has been widely recognised that being out of work is bad for health at a population level, and remaining in work may have positive health benefits. ${ }^{3}$

GPs in the UK are the initial gatekeepers to the benefit system by issuing sickness certificates after 1 week of self-certified absence. A 'Statement of Fitness for Work for social security or Statutory Sick Pay' enables people to stay off work in the early stages of illness without losing income until Work Capability Assessment can be conducted within 13 weeks. ${ }^{4}$ It is recognised that it is difficult for people who have been receiving benefits for a long time to get off benefits and back to work, and so recent policy has focused on trying to prevent people going on to long-term benefits.

In April 2010, a new sickness certificate (Med 3) or 'fit note' was introduced with the intention of reducing the number of people going on to long-term benefits. ${ }^{5}$ As well as recording patients' conditions, this certificate requires GPs to state if they have advised patients that they are not fit for work or may be fit for work, taking into account advice about whether the patient will benefit from a phased return to work, amended duties, altered hours, or workplace adaptations. There is also space for the GP to comment on the functional effects of the patient's condition.

The jury is still out about the utility of the new Med 3 and, anecdotally, the views of GPs about this initiative are mixed.
The additional requirements placed on GPs to complete the new Med 3 mean that they need to spend more time finding out what their patients' work actually entails. Arguably, for this initiative to be effective in keeping people in work when they are ill, it also requires GPs to have a knowledge and understanding of a range of workplaces, and the possible adaptations that can be implemented. Only about one in 25 GPs has any special training in occupational health, and most do not have the knowledge required to understand the working lives of all of their patients. ${ }^{6}$

There is little published research in this area, and so the study by Money and colleagues in this edition of the BJGP is welcome. ${ }^{7}$ These researchers report the findings of telephone interviews with 30 GPs who have a Diploma in Occupational Medicine and who reported a case of work-related ill-health to The Health and Occupation Reporting network in General Practice (THOR-GP). These GPs reported that patients more often initiated discussions about requests for sickness absence than the GPs, and this proportion was greater when the illness was due to mental ill-health.

The involvement of GPs in sickness certification is known to be a cause of conflict between GPs' perceived role as patient advocates and that of gatekeepers to the benefit system. ${ }^{8}$ In the study by Money and colleagues, the negotiation for a sickness certificate was confirmed as a source of conflict, and some of the GPs reported avoiding this by routinely agreeing to patients' demands for a certificate.

Other GPs who resisted demands for a certificate felt that their occupational health training had given them a greater understanding of work and health. They believed that they were better at assessing their patients' fitness to work and so issued fewer certificates as a result.

One possible recommendation based on the findings of this research is that all GPs should undertake postgraduate training in occupational health. However, this would be costly and potentially unpopular among GPs. In addition, there is currently no evidence that this strategy would reduce the costs to the economy of long-term incapacity for work.

Other research has indicated that there is no significant variation across practices in rates of patients going on to long-term benefits and out of work because of illhealth once other factors, such as socioeconomic deprivation, are taken into account. ${ }^{9}$ This suggests that, even where there are variations in initial rates of sickness certification, this may not make much difference to long-term benefit levels.

Money and colleagues conclude that GPs are prepared to embrace changes to the sickness certification system to facilitate the reduction of sickness absence, but the participants of this research are not a representative sample of GPs: they are trained to diploma level in occupational health and participate in THOR-GP. They have a particular interest and expertise in work-related health issues and yet, despite this, some of them are not prepared to compromise their relationship with the patient by refusing to give a certificate.

The 'fit note' will need to be embraced by all GPs to make a big difference and, as these researchers suggest, further work needs to look at the attitudes of the great majority of GPs (who have not had postgraduate training in occupational health) to find out if they are embracing the changes to sickness certification.

Any additional resources, in the current economic climate, may be more appropriately directed towards employers, rather than towards providing occupational health training for GPs. This could enable employers to make appropriate adaptations in the workplace to help sick employees remain in work, particularly for the increasing number of employees with mental health problems.

\section{Jillian Morrison,}

Professor of General Practice, University of Glasgow, Glasgow. 


\section{Provenance}

Commissioned; not peer reviewed.

\section{REFERENCES}

1. Freud D. Reducing dependency, increasing opportunity: options for the future of welfare to work. Leeds: Department of Work and Pensions, 2007. http://www.dwp.gov.uk/policy/welfarereform/legislation-and-key-documents/freud-report/ (accessed 5 Sep 2010).

2. Department of Work and Pensions. Employment Support Allowance. London: Department of Work and Pensions, 2008. http://www.dwp.gov.uk/employmentand-support/ (accessed 5 Sep 2010).

3. Black DC. Working for a healthier tomorrow. London: The Stationery Office, 2008

http://www.dwp.gov.uk/docs/hwwb-working-for-ahealthier-tomorrow.pdf (accessed 5 Sep 2010).
4. Department for Social Development in Northern Ireland. Healthcare professionals. Belfast: Department for Social Development, 2009.

http://www.dsdni.gov.uk/index/ssa/benefit_informatio $\mathrm{n} /$ ssaniesa/esa-healthcare-professionals.htm (accessed 5 Sep 2010).

5. Department for Work and Pensions. Fit note. London: Department for Work and Pensions, 2010.

http://www.dwp.gov.uk/fitnote/ (accessed 5 Sep 2010).

6. Elms J, O'Hara R, Pickvance S, et al. The perceptions of occupational health in primary care. Occ Med (Lond) 2005; 55(7): 523-527.

7. Money A, Hussey L, Thorley K, et al. Work-related sickness absence negotiations: GPs' qualitative perspectives. Br J Gen Pract 2010; 60(579): 721-728.

8. Hussey S, Hoddinott P, Wilson P, Dowell J, Barbour R. Sickness certification system in the United Kingdom: qualitative study of views of general practitioners in Scotland. BMJ 2004; 328(7431): 88
9. Whittaker W, Sutton M, Maxwell M, et al. Predicting which people with psychosocial distress are at risk of becoming dependent on state benefits: analysis of routinely available data. BMJ 2010; 341: c3838.

DOI:10.3399/bjgp10X515647

ADDRESS FOR CORRESPONDENCE

Jillian Morrison

General Practice and Primary Care,

1 Horselethill Road, Glasgow G12 9LX.

E-mail: Jill.morrison@glasgow.ac.uk 